\title{
NR4A1 is Involved in Fibrogenesis in Ovarian Endometriosis
}

\author{
Xinliu Zeng ${ }^{a}$ Zhang Yue ${ }^{b} \quad$ Ying Gao $^{a}$ Guosong Jiang ${ }^{c} \quad$ Fuqing Zeng \\ Ying Shao ${ }^{a}$ Jiayu Huang ${ }^{a}$ Minuo Yin ${ }^{a}$ Yajie Lia
}

aDepartment of Gynecology and Obstetrics, Union Hospital, Tongji Medical College, Huazhong University of Science and Technology, Wuhan, Hubei Province, 'bepartment of Cardiovascular Surgery, Union Hospital, Tongji Medical College, Huazhong University of Science and Technology, Wuhan, Hubei Province, 'Department of Urology, Union Hospital, Tongji Medical College, Huazhong University of Science and Technology, Wuhan, Hubei Province, China

\section{Key Words}

Endometriosis - Endometrial stromal cells • Fibrosis - TGF- $\beta 1 /$ NR4A1 • Phosphorylation • Csn-B

\begin{abstract}
Background/Aims: Excess fibrosis may lead to chronic pain, scarring, and infertility as endometriosis develops and progresses. The pathogenesis of endometriosis has been linked to transforming growth factor- $\beta$ (TGF- $\beta$ ), the most potent promoter of fibrosis. Methods: Levels of NR4A1 and P-NR4A1 protein in human endometrial and endometriotic tissue were assessed by western blotting and immunohistochemistry. The expression levels of fibrotic markers in stromal cells were evaluated by real-time PCR. The degree of fibrosis in mouse endometriotic lesions was detected by Masson trichrome and Sirius red staining. Results: The level of phosphorylated-NR4A1 was higher in ovarian endometriotic tissue than in normal endometrium, and long-term TGF- $\beta 1$ stimulation phosphorylated NR4A1 in an AKT-dependent manner and then promoted the expression of fibrotic markers. Furthermore, inhibition of NR4A1 in stromal cells increased the TGF- $\beta 1$-dependent elevated expression of fibrotic markers, and loss of NR4A1 stimulated fibrogenesis in mice with endometriosis. Additionally, Cytosporone B (Csn-B), an NR4A1 agonist, effectively decreased the TGF- $\beta 1$-dependent elevated expression of fibrotic markers in vitro and significantly inhibited fibrogenesis in vivo.
\end{abstract} Conclusion: NR4A1 can regulate fibrosis in endometriosis and may serve as a new target for the treatment of endometriosis.

\section{Introduction}

(C) 2018 The Author(s) Published by S. Karger AG, Basel

Endometriosis, which is characterized by the implantation and growth of endometrial glands and stroma on extra-uterine sites, is a common cause of pelvic pain and subfertility

$X$. Zeng and Z. Yue contributed equally to this work.

Ying Gao and Guosong Jiang

Department of Gynecology and Obstetrics, Union Hospital, Tongji Medical College,

Huazhong University of Science and Technology, Wuhan, Hubei Province (China)

Tel. +86 13971162266, E-Mail gaoyingpro@163.com 


\section{Cellular Physiology Cell Physiol Biochem 2018;46:1078-1090 and Biochemistry Published online: April 18, $2018 \quad \begin{aligned} & \text { DOI 10159/D2018 The Author(s). Published by S. Karger AG, Basel } \\ & \text { www.karger.com/cpb }\end{aligned}$ \\ Zeng et al.: Phosphorylation of NR4A1 Promotes the Fibrosis of Endometriosis}

in women of reproductive age [1]. Severe symptoms of endometriosis affect $6 \%-10 \%$ of the female population worldwide [2]. Among them, 50\%-60\% have pelvic pain and up to $50 \%$ have infertility [2]. Histologically, ectopic endometrial glands and stroma are encompassed by dense fibrous tissue $[3,4]$. Fibrogenesis is an important process in endometriosis and exerts a significant negative impact on patients with the condition. Previous studies demonstrated that excess fibrosis around endometriotic lesions leads to scarring, pain, and impaired tissue function [5, 6]. Furthermore, the ovarian cortex might be involved and consequently the follicle reserve can be reduced by severe fibrosis $[7,8]$.

Transforming growth factor-beta (TGF- $\beta$ ) is a multifunctional growth factor that plays important roles in the regulation of cell proliferation, angiogenesis, differentiation, and the immune response [9]. It is also believed to be a key molecule in the fibrotic process [10]. Overexpression of TGF- $\beta$ has been found in a number of fibrocontractive diseases, such as skin scarring [11], pulmonary fibrosis [12], and peritoneal adhesion [13]. On the other hand, blockage of TGF- $\beta$ suppresses experimentally induced fibrosis in the skin, lungs, and liver $[14,15]$. Previous studies have shown that, compared with their healthy counterparts, women with endometriosis have higher levels of TGF- $\beta$ in serum and peritoneal fluid [16, 17]. This elevated level of TGF- $\beta$ plays a crucial role in fibrosis in endometriosis [18].

NR4A1 (also known as TR3, Nur77m, or NGF-IB) belongs to the steroid/thyroid hormone receptor superfamily [19]. It is implicated in a wide array of cellular events, such as glucose and lipid metabolism [20,21], apoptosis [22], and vascular homeostasis [23]. As an immediate early gene, it is subject to alteration by multiple stimuli, including growth factors, inflammatory factors, and stress, in a variety of cells and organs [24]. NR4A1 has been shown to be a strong and important activator of the TGF- $\beta /$ Smad signaling pathway [25], and it also recruits a repressor complex containing SP1, SIN3A, CoREST, LSD1, and HDAC1 to the TGF- $\beta$ target gene, thereby forming a negative feedback loop [26]. However, the role of NR4A1 in the fibrosis of endometriosis has not yet been studied.

In this study, we examined the fibrosis markers alpha-smooth muscle actin (a-SMA), type 1 collagen 1 (COL1A1), connective tissue growth factor (CTGF), and fibronectin (FN) and found that inhibition of NR4A1 could promote TGF- $\beta 1$-induced overexpression of fibrotic markers in human ectopic endometrial stromal cells (EESCs) and normal endometrial stromal cells (NESCs). Our study also indicated that Cytosporone B (Csn-B), a selective agonist that activates NR4A1 [27], could effectively decrease the TGF- $\beta 1$-induced elevated expression of fibrosis markers in vitro. Animal experiments showed that a lack of NR4A1 promoted the progression of fibrosis and that Csn-B effectively suppressed fibrogenesis in mouse endometriotic tissue. We are led to conclude that NR4A1 may be a therapeutic target for the treatment of fibrosis in endometriosis.

\section{Materials and Methods}

\section{Tissue sample collection}

Tissue samples were obtained from patients aged 20-41 years who underwent laparoscopy for ovarian endometriosis and hysteroscopy for primary infertility. None of them had received hormonal treatments in the prior 6 months, and all of them had regular menstrual cycles (26-32 days). Endometriotic tissues were taken from 23 patients (age: median, 31.0 years; range, 20-41 years) who had histopathologically proven endometriosis. In addition, proliferative-phase endometrial tissues were collected from 15 women without endometriosis (age: median, 29.5 years; range, 24-36 years) during the hysteroscopy by using an endometrial curette. Each sample was divided into three portions, with one portion fixed in $4 \%$ paraformaldehyde and embedded in paraffin, one frozen at $-80^{\circ} \mathrm{C}$ for western blotting, and one stored in Dulbecco's modified Eagle's medium (DMEM)/F-12 (Hyclone, Logan, UT) for cell isolation. The research protocol was approved by the Ethics Committee of Tongji Medical College, Huazhong University of Science and Technology, Wuhan, China. Prior to tissue collection, written informed consent was obtained from each participant. 


\section{Cellular Physiology Cell Physiol Biochem 2018;46:1078-1090 and Biochemistry Published \begin{tabular}{l|l} 
DOI: 10.1159/000488838 & $\begin{array}{l}\text { C } 2018 \text { The Author(s). Published by S. Karger AG, Basel } \\
\text { www.karger.com/cpb }\end{array}$
\end{tabular} \\ Zeng et al.: Phosphorylation of NR4A1 Promotes the Fibrosis of Endometriosis}

Cell isolation and culture

After being washed 3-5 times with phosphate-buffered saline (PBS; Hyclone,) to remove traces of blood, tissues collected from both women with endometriosis and healthy women were manually minced into 1-2 $\mathrm{mm}^{3}$ fragments and incubated in DMEM/F-12 with $0.2 \%$ type II collagenase (Sigma-Aldrich, St. Louis, MO) for $60 \mathrm{~min}$ at $37^{\circ} \mathrm{C}$. Stromal cells were separated from epithelial cells by filtration through a 40- $\mu$ m nylon strainer (BD Falcon, San Jose, CA), as described previously [28]. The isolated cells were plated into Primaria flasks (Corning, Corning, NY) containing DMEM/F-12 [consisting of 20\% fetal bovine serum (ScienCell, San Diego, CA), $0.1 \mathrm{mg} / \mathrm{mL}$ streptomycin, $100 \mathrm{U} / \mathrm{mL}$ penicillin, and $0.25 \mu \mathrm{g} / \mathrm{mL}$ amphotericin B (Sigma-Aldrich)] and incubated at $37^{\circ} \mathrm{C}$ in $95 \%$ air plus $5 \% \mathrm{CO}_{2}$. Red blood cells were removed by PBS 24 $\mathrm{h}$ later. The cells reached confluence in about 3 days, and cells of 2-3 passages were used for experiments. To determine the purity and homogeneity of EESCs and NESCs, immunofluorescent staining was performed using antibodies against vimentin (GB13225, Servicebio, Wuhan, China), CD10 (23898-1-AP, Proteintech, Wuhan, China), cytokeratin 7 (GB11066, Servicebio), and CD45 (GB11192, Servicebio). The purity of stromal cells was $>95 \%$ as assessed by positive staining for vimentin and CD10 and negative staining for cytokeratin 7 and CD45.

\section{NR4A1 siRNA transfection}

EESCs and NESCs were seeded in culture media $24 \mathrm{~h}$ before transfection into 60 -mm dishes $\left(4 \times 10^{5}\right.$ cells per well) for western blotting, 6-well plates $\left(2 \times 10^{5}\right.$ cells per well) for quantitative real-time RT-PCR, or 24-well plates $\left(2 \times 10^{4}\right.$ cells per well) for immunofluorescence. siRNA transfection was carried out in serum-free DMEM/F-12 by using NEOFECT ${ }^{\mathrm{TM}}$ DNA transfection reagent (NEOFECT, Beijing, China) and 20 nM siRNA. The siRNA sequences were as follows: S1, GGACAGAGCA GCUGCCCAAdTdT; S2, CAGUCCAGCC AUGCUCCUCdTdT. Control siRNA or validated human NR4A1 siRNAs (GENE, Shanghai, China) were mixed into the culture media and incubated for $24 \mathrm{~h}$ for quantitative real-time RT-PCR or for $48 \mathrm{~h}$ for western blotting and immunofluorescence. Mock-transfected cells were used as a negative control. They were treated with 5 ng/mL TGF- $\beta 1$ (PeproTech, Rocky Hill, NJ [29]) 6 h after siRNA transfection.

\section{RNA isolation and complementary DNA synthesis}

After being incubated with Csn-B (1 $\mu \mathrm{mol}$; Santa Cruz Biotechnology, Santa Cruz, CA [26]), siRNA, and TGF- $\beta 1$ for $24 \mathrm{~h}$, total RNA from cells was extracted with Invitrogen TRIzol reagent (Invitrogen, Carlsbad, CA) according to the manufacturer's instructions. RNA quantification and purification were carried out at a 260/280 ratio on a NanoDrop 2000 spectrophotometer (NanoDrop Technologies, Wilmington, DE). A 260/280 ratio ranging from 1.8 to 2.0 was regarded as satisfactory purity. Complementary DNA was synthesized from total RNA using a reverse transcription PrimeScript RT Reagent Kit (Takara Biomedical Technology, Dalian, China).

\section{Quantitative real-time PCR}

The gene expression levels of a-SMA, COL1A1, CTGF, and FN were determined by quantitative realtime PCR using the SYBR Premix Ex Taq kit (Takara Biomedical Technology). The PCR was performed in duplicate and run on a StepOnePlus Real-Time PCR System (Applied Biosystems, Foster City, CA). As an internal housekeeping control gene, GAPDH served to normalize the amount of cDNA within each sample. The primer sequences are listed in Table 1. Experiments were performed three times.

\section{Western blot analysis}

After being incubated with Csn-B, TGF- $\beta 1$, and MK2206 (100 $\mu \mathrm{m}$; Selleck Chemicals, Houston, TX [30]), proteins from cells were extracted, electrophoresed on sodium dodecyl sulfatepolyacrylamide gels, and transferred to polyvinylidene difluoride membranes (PVDF; Millipore Corp., Bedford, MA).
Table 1. Sequences of primers used for RT-PCR analysis

\begin{tabular}{lcr}
\hline Gene & Forward primer sequence & Reverse primer sequence \\
\hline GAPDH & 5'-TCACCACCATGGAGAAGGC-3' & 5'-GCTAAGCAGTTGGTGGTGCA-3' \\
a-SMA & 5'-GGCCGAGATCTCACTGACTAC-3 & 5'-TTCATGGATGCCAGCAGA-3' \\
COL1A1 & 5'-CAGCCGCTTCACCTACAGC-3' & 5'-TTTTGTATTCAATCAGTGTCTTGCC-3' \\
CTGF & 5'-TTGGCCCAGACCCAACTATG-3' & 5'-CAGGAGGCGTTGTCATTGGT-3' \\
FN & 5'-GGGAGCCTCGAAGAGC-3' & 5'-AACAAGTACAAACCAACGCA-3' \\
\hline
\end{tabular}




\section{Cellular Physiology Cell Physiol Biochem 2018;46:1078-1090 and Biochemistry Published online: April 18, $2018 \quad \begin{aligned} & \text { DOI: 10.1159/000488838 } 2018 \text { The Author(s). Published by S. Karger AG, Basel } \\ & \text { www.karger.com/cpb }\end{aligned}$ \\ Zeng et al.: Phosphorylation of NR4A1 Promotes the Fibrosis of Endometriosis}

After blockage with 5\% nonfat milk for $1 \mathrm{~h}$ in Tris-buffered saline containing $0.1 \%$ Tween-20 (TBST), the membranes were incubated at $4^{\circ} \mathrm{C}$ overnight with primary antibodies against NR4A1 (1:400 dilution; no. 3960, Cell Signaling Technology), phosphorylated-NR4A1 (P-NR4A1; 1:200 dilution; no. sc-16992, Santa Cruz Biotechnology), AKT (1:1000 dilution; no. 4691, Cell Signaling Technology), and phosphorylated AKT (P-AKT; 1:1000 dilution; no. 4060, Cell Signaling Technology). The membranes were washed with TBST for $30 \mathrm{~min}$ and then immunoblotted with HRP-conjugated secondary antibodies (Proteintech) at room temperature for $1 \mathrm{~h}$. Blots were developed by enhanced chemiluminescence (ECL; Beyotime, Beijing, China). Autoradiograms were densitometrically determined by using the Quantity One software package (Bio-Rad, Hercules, CA). GAPDH was used as a loading control and was visualized using monoclonal antibodies against GAPDH (1:1000 dilution; no. 60004-1-Ig, ProteinTech). Western blots were analyzed using ImageJ software (version 1.41). Experiments were performed three times.

\section{Immunohistochemistry}

Formalin-fixed, paraffin-embedded human and mouse tissue sections were deparaffinized in xylene and rehydrated. The tissue slides were incubated with fresh prewarmed antigen retrieval buffer, and the buffer was heated to boiling. The tissue slides were then equilibrated to room temperature for $30 \mathrm{~min}$. After being added to $3 \% \mathrm{H}_{2} \mathrm{O}_{2}$ and rinsed with PBS, the slides were incubated with antibodies against NR4A1 (1:50 dilution; no. PAB11925, Bio-Swamp) or P-NR4A1 (1:100 dilution; no. sc-16992, Santa Cruz Biotechnology) at $4^{\circ} \mathrm{C}$ overnight. HRP-conjugated antibodies (ZSGB-BIO, Beijing, China) were used as secondary antibodies. After three washes with PBS, the tissue slides were incubated with the secondary antibody for $30 \mathrm{~min}$ at room temperature. Finally, the slides were color-reacted with DAB and counterstained with hematoxylin. To quantify immunostained cells, we used a computerized image analysis system consisting of an automatic digital slide scanner (Pannoramic Midi II; 3DHistech, Budapeste, Hungary) and an image-viewing software (Pannoramic Viewer; 3DHistech). The immunostained score (percentage of immunostained surface $\times$ mean staining intensity) was computed [31]. In each sample, 10 non-overlapping fields were analyzed.

\section{Immunofluorescence staining}

For immunofluorescence, 4\% PFA-fixed, 0.25\% Triton X-100-permeabilized EESCs and NESCs were incubated with antibodies against NR4A1 (1:100 dilution; no. sc-5569, Santa Cruz Biotechnology) and a-SMA (1:100 dilution; no. ab7817, Abcam) at $4^{\circ} \mathrm{C}$ overnight after treatment with TGF- $\beta 1$, Csn-B, or NR4A1 siRNA. Fluorescent antibodies (1:200 dilution; no. 150105 and 150075, Abcam, Cambridge, UK) were used as secondary antibodies. Cell nuclei were stained by using DAPI (ZSGB-BIO). In addition, F-actin was dyed with FITC-Phalloidin (Sigma-Aldrich). Stained cells were observed under a Nikon Eclipse 80i microscope (Nikon, Louisville, KY).

\section{Mouse model of endometriosis}

NR4A1\% mice (B6;129S2-Nr4a $1^{\text {tm1jmi } / J) ~ w e r e ~ p u r c h a s e d ~ f r o m ~ J a c k s o n ~ L a b o r a t o r y ~(B a r ~ H a r b o r, ~ M E) . ~}$ Female NR4A1\% and littermate wild-type controls (WT; 7-8 weeks old, 23-25 g) were used in this study. Female nude mice (7-8 weeks old, 20-23 g) were procured from Vital River Laboratory Animal Technology Co. Ltd. (Beijing, China). The mice were maintained in autoclaved cages at $26^{\circ} \mathrm{C}$ with regular 12 -h light-dark cycles and were fed sterile food and water. All procedures for the mouse experiments were reviewed and approved by the Animal Care Committee of Tongji Medical College, Wuhan, China.

\section{NR4A1-/- and WT mouse endometriosis model}

Endometriotic lesions were experimentally induced by auto-transplantation of uterine horn tissue into the peritoneal cavity as previously described [32]. Briefly, animals were anesthetized by intraperitoneal injection of pentobarbital sodium ( $40 \mathrm{mg} / \mathrm{kg}$; Solarbio, Beijing, China). A mid-ventral incision was made to expose the uterus. The horn was securely ligated at the utero-cervical junction and at the uterotubal junction, and then the part of the uterus between the two ligations was excised. The uterine horn, after being opened longitudinally, was placed in PBS and cut into four pieces measuring approximately 3-4 $\mathrm{mm}^{2}$. Four tissue blocks of equal size from one uterine horn were transplanted onto the abdominal wall and anchored with 8-0 suture. The skin and peritoneum were closed with 5-0 suture. 17- $\beta$-estradiol-3-benzoata (30 $\mathrm{\mu g} / \mathrm{kg}$; Aladdin, Shanghai, China) was intramuscularly injected at the time of surgery and every 3 days thereafter [33] for 21 days. The mice were sacrificed on day 21 for collection of endometriotic implants. 


\section{Cellular Physiology Cell Physiol Biochem 2018;46:1078-1090 and Biochemistry Published online: April 18, $2018 \quad \begin{aligned} & \text { DOI: 10.1159/000488838 } 2018 \text { The Author(s). Published by S. Karger AG, Basel } \\ & \text { www.karger.com/cpb }\end{aligned}$ \\ Zeng et al.: Phosphorylation of NR4A1 Promotes the Fibrosis of Endometriosis}

Nude mouse model of endometriosis

A nude mouse endometriosis model was established as previously described [34]. Endometrial tissue from 8 patients without endometriosis was collected, placed in sterile PBS, and then minced. Next, $0.5 \mathrm{~mL}$ of 10 endometrial fragments at the proliferation phase (1-2 $\left.\mathrm{mm}^{3}\right)$ was injected subcutaneously into nude mice by 18-gauge needles. The mice were randomly divided into two groups after the injection. The first group of 30 mice was used for examining the changes in NR4A1 and P-NR4A1 during the development of endometriosis. 17- $\beta$-estradiol-3-benzoata was injected at the time of the endometrial tissue implantation and at 3-day intervals. The mice were sacrificed for tissue collection on days 3, 5, 7, 14, and 21. The second group of 30 mice was randomly further divided into two subgroups. In the first subgroup, the NR4A1 agonist Csn-B (Sigma-Aldrich), dissolved in dimethyl sulfoxide (DMSO; Sigma-Aldrich), was injected into the abdominal cavity at a dosage of $13 \mathrm{mg} / \mathrm{kg}$ twice weekly [27]. Animals in the second subgroup were injected with the same solvent without Csn-B. Treatment with Csn-B or DMSO started on the day of implantation. 17 - $\beta$-estradiol-3-benzoata was injected at the time of the endometrial tissue implantation and every 3 days thereafter for 21 days. The mice were sacrificed for tissue collection on day 21.

\section{Histology}

Paraffin-embedded endometriotic tissue sections were stained with Masson trichrome, Sirius red, and hematoxylin as previously described [35]. Sirius red and Masson were quantified according to the staining intensity $[36,37]$. The staining was scored from 0 to 4 ( 0 indicated no staining, 4 indicated maximal staining). Ten non-overlapping fields were analyzed

\section{Statistical analysis}

GraphPad Prism 5 (GraphPad Software Inc., San Diego, CA) was used for statistical analysis. Comparisons between different groups were made using the Student's $t$-test and Kruskal-Wallis test. Statistical significance was set at $\mathrm{P}<0.05$.

\section{Results}

Long-term stimulation with TGF- $\beta 1$ phosphorylates NR4A1 in NESCs and EESCS

Western blotting was performed to determine NR4A1 and P-NR4A1 expression levels in 15 normal endometrial and 23 ovarian endometriotic tissue samples. No significant differences were observed in the total NR4A1 level between endometrial and endometriotic tissue (Fig. 1A). Furthermore, treatment with antibodies conjugated to its phosphorylated form (P-NR4A1) showed that NR4A1 phosphorylation was augmented in endometriotic tissue compared with endometrial tissue (Fig. 1A). Immunohistochemical analysis of 15 normal endometrial and 23 ovarian endometriotic tissue samples showed that endometriotic stromal cells had higher expression of P-NR4A1 than endometrial stromal cells (Fig. 1B). Then, we cultured NESCs extracted from normal endometrial tissue and EESCs from endometriotic tissue to determine whether the expression of NR4A1 and P-NR4A1 in stromal cells was altered by TGF- $\beta 1$ stimulation. By exposing NESCs and EESCs to TGF- $\beta 1$ for $96 \mathrm{~h}$ as a persistent stimulation, the level of NR4A1 protein from NESCs began to rise at $12 \mathrm{~h}$ and then decreased to control levels within $72 \mathrm{~h}$; the level of NR4A1 protein from EESCs began to increase at $6 \mathrm{~h}$ and then decreased, but had still not reached the control level by $96 \mathrm{~h}$ (Fig. 1C). Meanwhile, under identical experimental conditions, the concentration of P-NR4A1 in both NESCs and EESCs rose steadily over time (Fig. 1C). Immunofluorescent staining showed that the expression of NR4A1 in NESCs was upregulated at $24 \mathrm{~h}$ compared with $0 \mathrm{~h}$ and had decreased to control levels by $72 \mathrm{~h}$ (Fig. 1D). Taken together, these data showed that longterm stimulation with TGF- $\beta 1$ promoted the phosphorylation of NR4A1 in NESCs and EESCs.

Inhibition of NR4A1 promotes the expression of a-SMA, FN, COL1A1, and CTGF in TGF- $\beta 1$ treated NESCS and EESCS

To understand the role of reduced NR4A1 function in the pathogenesis of fibrosis in endometriosis, NESCs and EESCs were transfected with NR4A1 siRNA. We studied two NR4A1 siRNAs. Experiments in NESCs indicated that NR4A1 siRNA of S1 lowered NR4A1 
Fig. 1. Expression of NR4A1 and P-NR4A1 in human endometriotic tissues and stromal cells incubated with TGF- $\beta 1$. A, NR4A1 and P-NR4A1 proteins in normal endometrial tissue $(\mathrm{N})$ and ovarian endometriotic tissue (E). Relative expression levels of protein standardized by GAPDH are expressed as the mean \pm SD. B, Representative photomicrographs of NR4A1 and P-NR4A1 in normal endometrial tissues and ovarian endometriotic tissues. C, After persistent stimulation with TGF- $\beta 1$, the expression of NR4A1 and P-NR4A1 in NESCs and EESCs. Relative expression of protein in NESCs and EESCs under TGF- $\beta$ stimulation at each time point standardized by GAPDH is given as the mean \pm SD $\left({ }^{*} \mathrm{P}<0.05\right)$. $\mathrm{D}$, Immunofluorescent staining showing the level of NR4A1 in NESCs when treated with TGF- $\beta$ at different time points (scale bars, $50 \mu \mathrm{m})$.

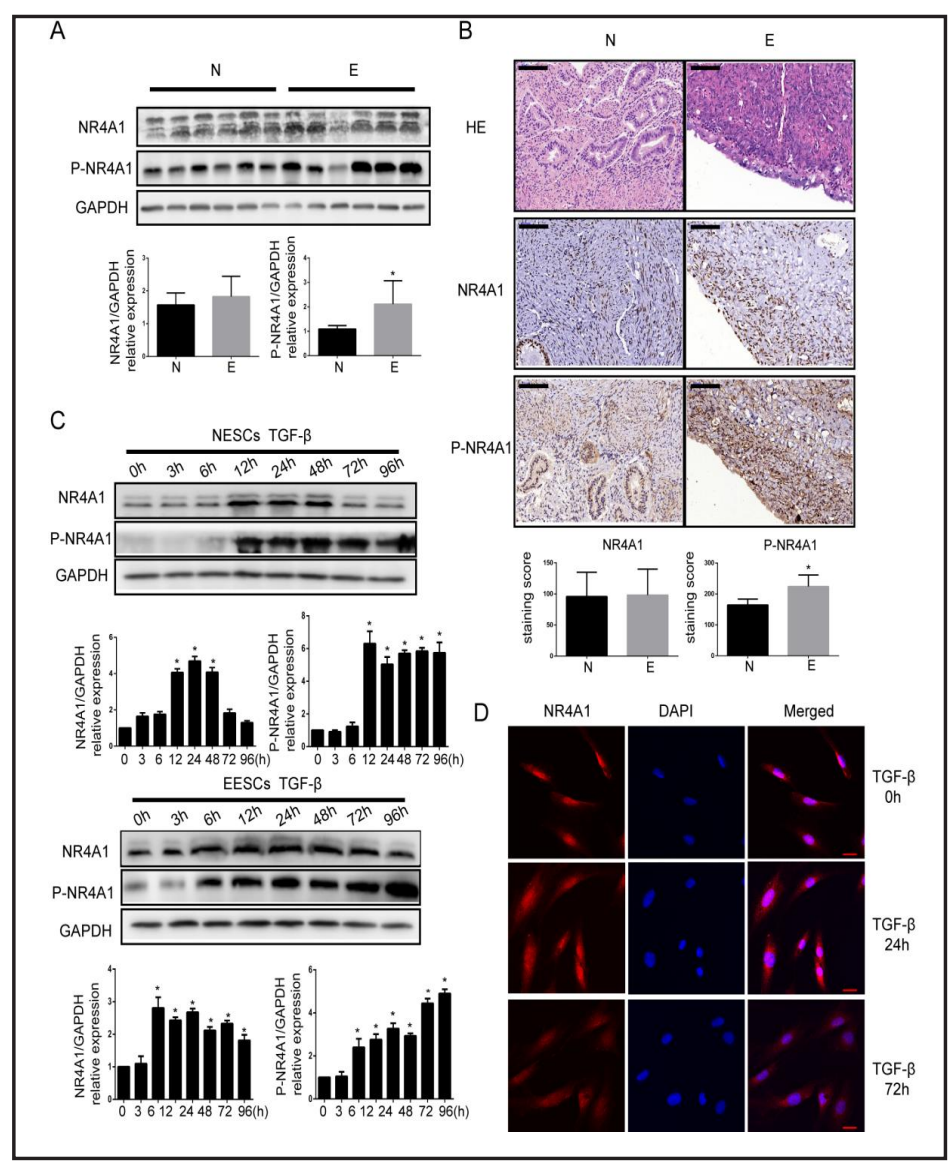

protein expression by $30 \%(\mathrm{P}<0.01)$ and that NR4A1 siRNA of $\mathrm{S} 2$ reduced the level of NR4A1 protein by $40 \%(\mathrm{P}<0.01)$ (Fig. 2A). Both S1- and S2-transfected NESCs had lower expression of NR4A1 mRNA compared with mock-transfected cells (Fig. 2B). The immunofluorescent staining showed that NR4A1 siRNA S2 transfection led to a higher expression of a-SMA and increased the formation of stress fibers in TGF- $\beta 1$-treated NESCs (Fig. 2C). After incubation with TGF- $\beta 1$, the mRNA expression of a-SMA, FN, COL1A1, and CTGF was increased in S2transfected NESCs and EESCs (Fig. 2D). Collectively, these data indicated that the decreased NR4A1 promoted the expression of fibrosis markers in TGF- $\beta 1$-treated NESCs and EESCs.

Csn-B suppresses the TGF- $\beta 1$-dependent increase in the production of a-SMA, FN, COL1A1, and CTGF in vitro

In order to further explore whether the activation of NR4A1 could decrease fibrosis in vitro, we incubated stromal cells with TGF- $\beta 1$ and Csn-B. Western blotting results showed that Csn-B significantly decreased the TGF- $\beta 1$-induced phosphorylation of NR4A1 and marginally increased the expression of NR4A1 in NESCs (Fig. 3A). Immunofluorescence staining revealed that treatment with Csn-B significantly reduced the expression of a-SMA and the formation of stress fibers induced by TGF- $\beta 1$ in NESCs (Fig. 3B). In addition, treatment with Csn-B significantly decreased the TGF- $\beta 1$-dependent increase in the expression of a-SMA, FN, COL1A1, and CTGF mRNA in both endometrial and endometriotic stromal cells (Fig. 3C).

TGF- $\beta 1$-induced phosphorylation of NR4A1 acts through an AKT-dependent mechanism

To investigate whether AKT participates in the TGF- $\beta 1$-induced phosphorylation of NR4A1, we incubated NESCs with TGF- $\beta 1$ and MK2206 (an inhibitor of AKT). MK2206 significantly decreased the level of phosphorylated AKT and, at the same time, reduced the phosphorylation of NR4A1 (Fig. 4A). These data showed that AKT is involved in the TGF- $\beta 1$ induced phosphorylation of NR4A1 in NESCs. 


\section{Cellular Physiology Cell Physiol Biochem 2018;46:1078-1090 \begin{tabular}{ll|l} 
DOI: 10.1159/000488838 & (0 2018 The Author(s). Published by S. Karger AG, Basel \\
www.karger.com/cpb
\end{tabular} \\ Zeng et al.: Phosphorylation of NR4A1 Promotes the Fibrosis of Endometriosis}

NR4A1 and P-NR4A1 levels change during the development of endometriotic lesions in mice

The expression of NR4A1 and P-NR4A1 during the development of endometriosis was determined in 30 nude mice. Ten human endometrial fragments were subcutaneously injected into each nude mouse. On day 21, 3-5 endometriotic lesions were found under the skin in each mouse. Five nude mice were evaluated in each group. Immunohistochemical staining using NR4A1 antibody indicated that the level of NR4A1 was significantly higher on day 5 and 7 than on day 0 and 3. On the other hand, the expression of NR4A1 on day 14 and 21 was decreased compared with day 5 and 7, but the level remained higher than

Fig. 2. Inhibition of NR4A1 promotes the expression of fibrosis markers in vitro. A, The expression of NR4A1 in NESCs after incubation with NR4A1 siRNAs si1 and si2. Relative expression of NR4A1 standardized by GAPDH is presented as the mean \pm SD $\left({ }^{*} \mathrm{P}<0.05\right) . B$, Effect of NR4A1 siRNAs on the expression of NR4A1 mRNA in NESCs $\left({ }^{*} \mathrm{P}<0.05\right) . \mathrm{C}$, Immunofluorescence staining showing the production of a-SMA and stress fibers in si2transfected NESCs after incubation with TGF- $\beta 1$ (scale bars, $25 \mu \mathrm{m}$ ). $D$, RT-PCR showing upregulation of the TGF- $\beta 1$-dependent elevated expression of a-SMA, FN, COL1A1, and CTGF mRNA in si2-transfected NESCs and EESCs $\left({ }^{*} \mathrm{P}<0.05\right)$.

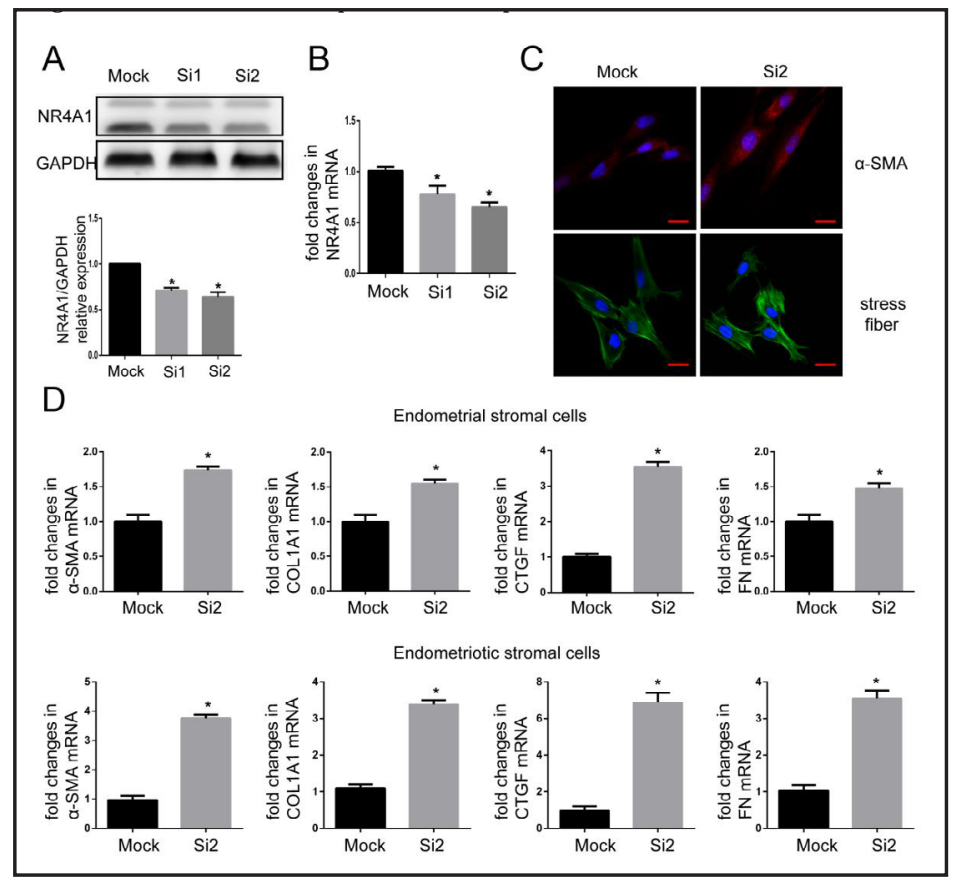

Fig. 3. Csn-B attenuates the expression of fibrosis markers in vitro. A, Csn-B (1 $\mu \mathrm{M}$ ) activated NR4A1 by increasing the level of NR4A1 and decreasing the level of P-NR4A1. Relative expression levels of NR4A1 and P-NR4A1 standardized by GAPDH are expressed as the mean \pm SD $\left({ }^{*} \mathrm{P}<0.05\right)$. B, Immunofluorescence staining showing the level of a-SMA and stress fibers in different groups (scale bars, $25 \mu \mathrm{m}$ ). C, RT-PCR showing that a-SMA, FN, COL1A1, and CTGF mRNA in TGF- $\beta$ incubated $(5 \mathrm{ng} / \mathrm{ml})$ stromal cells were overexpressed compared with control and that Csn-B counteracted the effect. All experiments were conducted in triplicate $\left({ }^{*} \mathrm{P}<0.05\right)$.

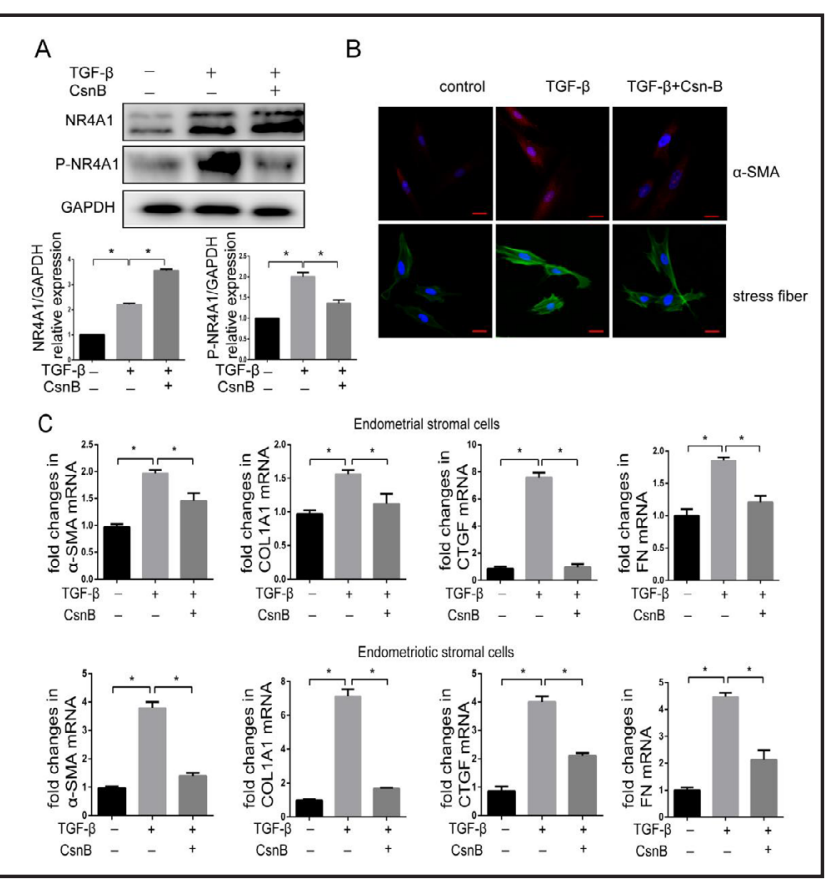




\section{Cellular Physiology Cell Physiol Biochem 2018:46:1078-1090 and Biochemistry Published onl004ne: April 18, $2018 \quad \begin{aligned} & \text { DOI 1018 2018 The Author(s). Published by S. Karger AG, Basel } \\ & \text { www.karger.com/cpb }\end{aligned}$ \\ Zeng et al.: Phosphorylation of NR4A1 Promotes the Fibrosis of Endometriosis}

that on day 0 (Fig. 5A). Furthermore, immunohistochemical staining using P-NR4A1 antibody indicated that the level of P-NR4A1 started to increase on day 5 and rose steadily during the development of endometriotic lesions (Fig. 5A).

Loss of NR4A1 stimulates fibrogenesis in mice with endometriosis

To investigate the loss of NR4A1 function in endometriosis-associated fibrosis in vivo, endometriosis was surgically induced in NR4A1\% and littermate WT control mice by autotransplantation of uterine tissue (Fig. 6A). All of the mice developed endometriosis with endometriotic tissue containing stromal and glandular cells. Western blotting and immunohistochemical staining using NR4A1 antibody showed that NR4A1\% ectopic lesions had weak NR4A1 expression (Fig. 6B and C). NR4A1' 1- ectopic lesions were strongly stained by Sirius red and Masson trichrome staining (Fig. 6C). The results suggested that loss of NR4A1 promoted fibrogenesis in mice with endometriosis.

\section{Csn-B attenuates fibrosis in nude mice with endometriosis}

A mouse endometriosis model was established by xenograft (Fig. 7A). Animals were monitored on a daily basis and body weight was recorded. No significant difference was found in growth rate between Csn-B-treated and untreated mice. The numbers and sizes of the endometriotic lesions were also not significantly different between the two groups on day 21 . However, western blotting and immunohistochemistry indicated that Csn-B-treated mice had a higher level of total NR4A1 and lower level of P-NR4A1 in endometriotic lesions (Fig. 7B and $\mathrm{C}$ ), and the endometriotic tissues in Csn-B-treated mice were weakly stained by Sirius red and Masson trichrome staining (Fig. 7C). Collectively, these data indicated that Csn-B effectively inhibited the fibrogenesis in nude mice with endometriosis.

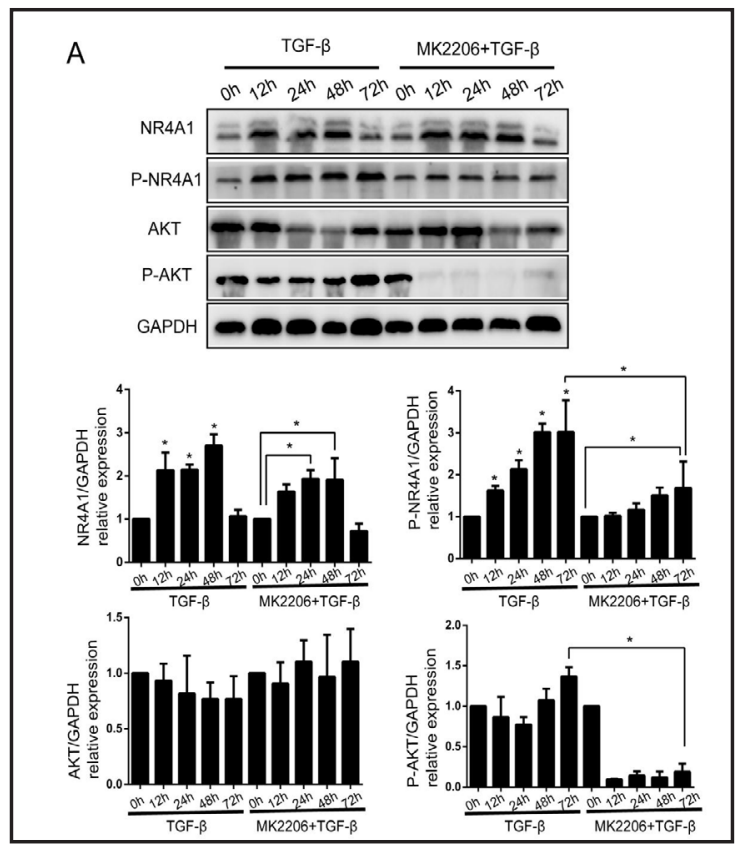

Fig. 4. AKT is implicated in the phosphorylation of NR4A1. A, MK2206 decreased the phosphorylation of NR4A1. The ratio of each protein relative to TGF- $\beta 10 \mathrm{~h}$ and TGF- $\beta 1+$ MK2206 0 h was normalized against GAP$\mathrm{DH}$. Relative expression levels of proteins standardized by GAPDH are given as the mean $\pm \mathrm{SD}\left({ }^{*} \mathrm{P}<0.05\right)$.

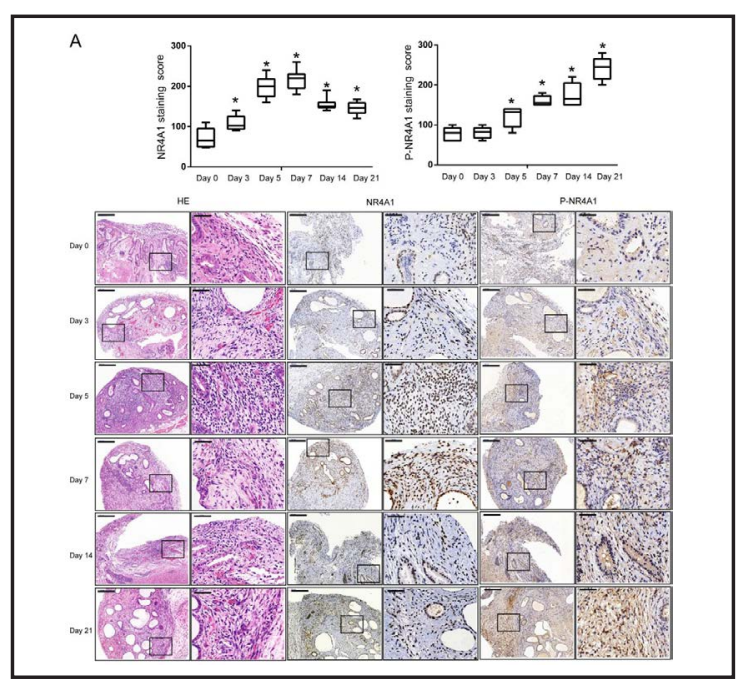

Fig. 5. Levels of NR4A1 and P-NR4A1 during the development of endometriotic lesions. A, Representative photomicrographs of NR4A1 and P-NR4A1 on days $0,3,5,7,14$, and 21 during the development of nude mouse endometriotic lesions. Photographs were taken at magnifications of 100 and 400 (scale bars, $50 \mu \mathrm{m}$ and $200 \mu \mathrm{m}$, respectively). Staining score is expressed as the mean $\pm \mathrm{SD}\left({ }^{*} \mathrm{P}<0.05\right)$. 


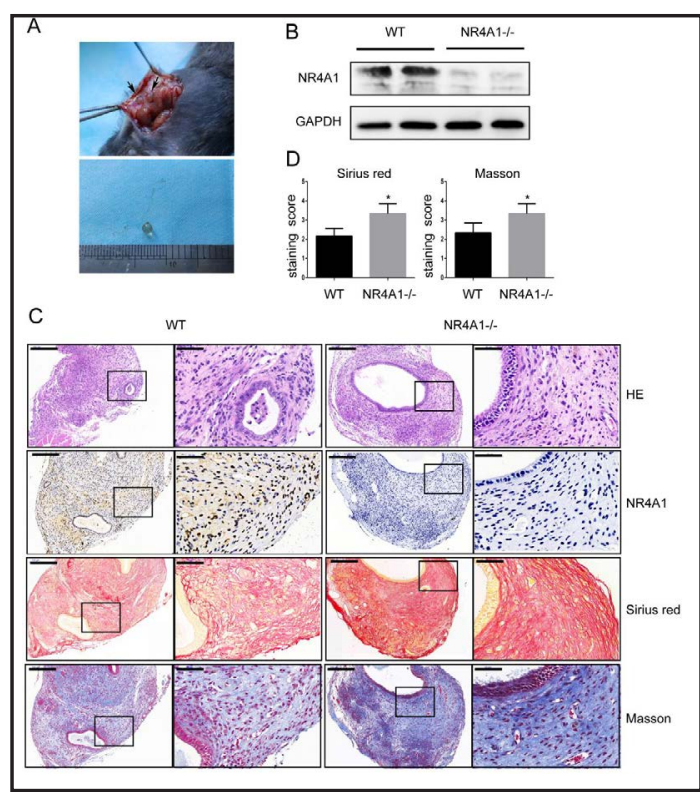

Fig. 6. Loss of NR4A1 exacerbates fibrogenesis in a mouse endometriosis model. A, In WT and NR4A1 /- mice, endometriosis was surgically induced by auto-transplantation of uterine tissue. B, Protein levels of NR4A1 in WT $(n=10)$ and NR4A1\% $(n=10)$ mouse endometriotic tissues as detected by western blotting. Relative expression of NR4A1 was standardized by GAPDH and is presented as the mean \pm SD $\left({ }^{*} \mathrm{P}<0.05\right)$. C, Representative photomicrographs of mouse endometriotic tissues stained with hematoxylin and eosin, NR4A1, Sirius red, and Masson trichrome. Photographs were taken at magnifications of 100 and 400 (scale bars, 50 $\mu \mathrm{m}$ and $200 \mu \mathrm{m}$, respectively). D, Staining score of Sirius red and Masson trichrome. Staining score is expressed as the mean \pm SD $\left({ }^{*} \mathrm{P}<0.05\right)$.

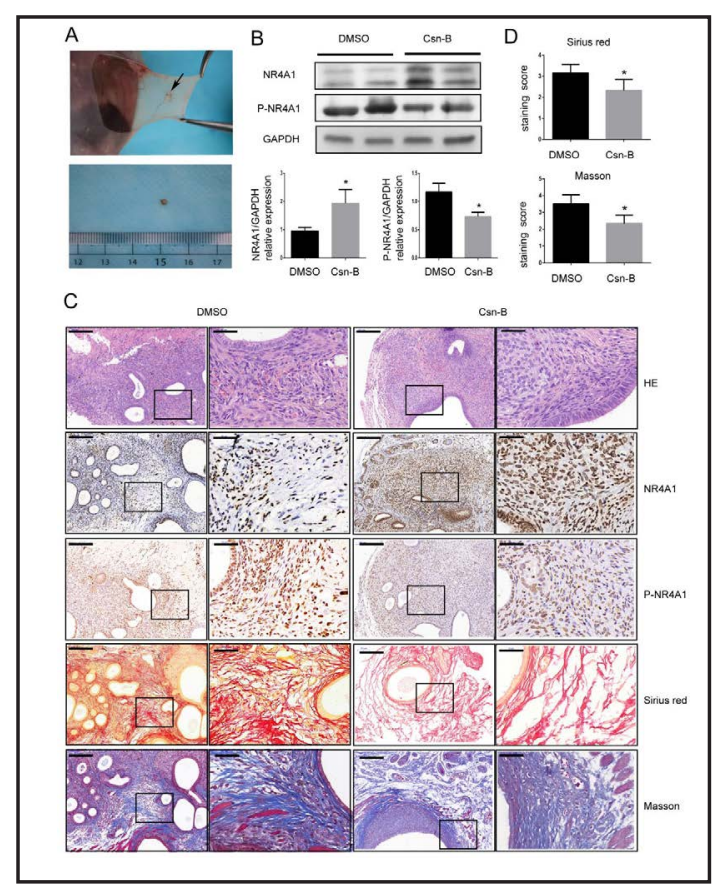

Fig. 7. Csn-B prevents fibrogenesis in a nude mouse model of endometriosis. A, Nude mouse endometriosis was induced by xenografting. The mice were randomly divided into control $(n=15)$ and Csn-Btreated $(n=15)$ groups. $B$, Western blotting was used to determine the levels of NR4A1 and P-NR4A1 proteins in mouse endometriotic tissue. Relative expression levels of NR4A1 and P-NR4A1 were standardized by GAPDH and are presented as the mean $\pm \mathrm{SD}$ $\left({ }^{*} \mathrm{P}<0.05\right) . \mathrm{C}$, Representative photomicrographs of mouse endometriotic tissues stained with hematoxylin and eosin, NR4A1, P-NR4A1, Sirius red, and Masson trichrome. Photographs were taken at magnifications of 100 and 400 (scale bars, $50 \mu \mathrm{m}$ and 200 $\mu \mathrm{m}$, respectively). D, Staining score of Sirius red and Masson trichrome. Staining score is expressed as the mean \pm SD $(* \mathrm{P}<0.05)$.

\section{Discussion}

This study demonstrated that persistent stimulation with TGF- $\beta 1$ phosphorylated NR4A1 in endometrial stromal cells through an AKT-dependent mechanism. NR4A1 deficiency promoted fibrosis in endometriosis and Csn-B antagonized this effect both in vitro and in vivo. These results may provide a new target for the treatment of endometriosis.

Tissues can be damaged after multiple acute or chronic stimulations, such as autoimmune reactions, infections, and mechanical injuries [38]. The repair process involves a regenerative phase and a fibrotic phase [38]. Hence, fibrosis is often regarded as an uncontrolled wound-healing response [39] and is characterized by the presence of abundant fibrous connective tissue [40]. TGF- $\beta$ is believed to be a key mediator in this process [41]. Although the pathogenesis of endometriosis is still unclear, one of the most widely accepted hypotheses is the implantation theory [1]. In this theory, endometriosis originates from retrograde menstruation of endometrial tissue, which passes through the fallopian tubes into the peritoneal cavity and implants in the peritoneal cavity or on the abdominal organs. 


\section{Cellular Physiology Cell Physiol Biochem 2018;46:1078-1090 \begin{tabular}{ll|l} 
DOI: 10.1159/000488838 & and Biochemistry Published online: April 18, 2018 & $\begin{array}{l}\text { O 2018 The Author(s). Published by S. Karger AG, Basel } \\
\text { www.karger.com/cpb }\end{array}$
\end{tabular} \\ Zeng et al.: Phosphorylation of NR4A1 Promotes the Fibrosis of Endometriosis}

The endometrial fragments proliferate and cause inflammation and adhesions [42]. Here, we see fibrosis in endometriosis as an uncontrollable healing response induced by TGF- $\beta 1$. Dysfunction of stromal cells after injury may regulate the fibrotic process [43]. Our study showed that stimulation with TGF- $\beta 1$ promoted the expression of fibrotic markers in NESCs and EESCs.

NR4A1 is a transcription factor expressed in various and tissues that serves a range of biological functions [44]. NR4A1 bi-directionally regulates gene expression by binding to the promoter of its downstream target gene $[44,45]$. NR4A1 has been implicated in hypercholesterolemia [46], bladder cancer growth [47], and other events. This study showed that inhibition of NR4A1 promoted the expression of fibrotic markers in vitro and that loss of NR4A1 exacerbated fibrosis in a mouse endometriosis model. These findings suggest that NR4A1 participates in the fibrogenesis of endometriosis. As a member of nuclear orphan receptors, NR4A1 has been shown to act independently of ligands [48]. Hence, the activity of NR4A1 could be regulated at both a protein level and a post-translational modification level, such as via phosphorylation [49]. In 1990, Fahrner found that NR4A1 could be phosphorylated [50], and subsequent studies confirmed this finding and further indicated that the activity of NR4A1 was decreased by phosphorylation [48, 51]. Jiang et al [52]. showed that patients with uterine adenomyosis had a lower level of NR4A1 expression in endometrial tissues compared with fertile controls. However, this study showed that expression of NR4A1 was not significantly different between endometriotic tissue from women with ovarian endometriosis and endometrial tissue from healthy women. Furthermore, the P-NR4A1 level was increased in endometriotic tissue. This discrepancy might be because the samples were from different sources.

Because a previous study found that the ratio of stromal cells to epithelial cells in endometriotic tissue was different from that in the endometrium [53], it is difficult to determine whether the different expression of NR4A1 and P-NR4A1 protein in the two kinds of tissues was caused by stromal cells. However, our immunohistochemical results indicated that stromal cells may contribute more to this difference. NR4A1 expression was higher on day 21 than on day 0 in the nude mouse endometriosis model, possibly because of the short time of endometriotic lesion development. AKT has been reported to phosphorylate NR4A1 in gastric cancer cells [54]. Our study showed that long-term stimulation with TGF- $\beta 1$ phosphorylated NR4A1 and that MK2206 could partly counteract this process. These findings indicated that AKT is involved in the post-translational regulation of NR4A1 in endometrial stromal cells.

Csn-B is isolated from an endophytic fungus named Dothiorella $s p$. Strain HTF3 [55]. It specifically binds to the ligand-binding domain of NR4A1 and then stimulates the transactivational activity of NR4A1 [27]. Moreover, Csn-B does not have any such effects in NR4A1-null mice or cells, suggesting that Csn-B is an agonist of NR4A1 [27]. Recent studies found that Csn-B reduced hypercholesterolemia-induced inflammation [46], strongly blocked the secretion of Salmonella pathogenicity-associated proteins [55], and inhibited the growth of androgen-dependent bladder cancer cells [47]. In the present study, Csn-B effectively decreased the expression of fibrosis markers in vitro and attenuated fibrogenesis in a nude mouse model of endometriosis. Therefore, Csn-B may be a drug candidate for the treatment of endometriosis. Because the endometriotic lesions of nude mice developed under the skin instead of in the ovary, the mouse model used in this study has severe limitations compared with human ovarian endometriosis. Considering that Csn-B is a natural product and may be difficult to extract on a large scale, analogs of Csn-B might be useful in future clinical applications.

\section{Conclusion}

Our study showed that persistent stimulation of endometriotic tissues with TGF- $\beta 1$ decreased the activity of NR4A1 through AKT-dependent phosphorylation. The devitalized NR4A1 lost its function as a depressor of TGF- $\beta 1$ signaling and promoted fibrogenesis in 


\section{Cellular Physiology Cell Physiol Biochem 2018;46:1078-1090 \begin{tabular}{l|l} 
and Biochemistry Published online: April 18, 2018 & $\begin{array}{l}\text { (c) } 2018 \text { The Author(s). Published by S. Karger AG, Basel } \\
\text { www.karger.com/cpb }\end{array}$
\end{tabular} \\ Zeng et al.: Phosphorylation of NR4A1 Promotes the Fibrosis of Endometriosis}

ovarian endometriosis. Csn-B treatment significantly reduced the expression of fibrotic markers in vitro and inhibited fibrogenesis in mouse endometriosis. This study suggests that NR4A1 is involved in the fibrosis of ovarian endometriosis and that Csn-B, an agonist of NR4A1, is a potential candidate for the treatment of endometriosis.

\section{Acknowledgements}

Y.G. and G.J. were principally responsible for the research design and performed analyses. X.Z. and Z.Y. were involved in the study design, experimentation, result analysis, and manuscript drafting. Y.S., J.H., M.Y., and Y.L. conducted the experiments. All authors approved the final version of the paper.

This work was supported by grants from the National Natural Science Foundation of China (No. 81472406 and No. 81272816).

\section{Disclosure Statement}

The authors declare no conflict of interest.

\section{References}

1 Giudice LC, Kao LC: Endometriosis. Lancet 2004;364:1789-1799.

2 Giudice LC: Clinical practice. Endometriosis. N Engl J Med 2010;362:2389-2398.

- 3 Nisolle M, Donnez J: Peritoneal endometriosis, ovarian endometriosis, and adenomyotic nodules of the rectovaginal septum are three different entities. Fertil Steril 1997;68:585-596.

-4 Itoga T, Matsumoto T, Takeuchi H, Yamasaki S, Sasahara N, Hoshi T, Kinoshita K: Fibrosis and smooth muscle metaplasia in rectovaginal endometriosis. Pathol Int 2003;53:371-375.

-5 Gordts S, Puttemans P, Gordts S, Brosens I: Ovarian endometrioma in the adolescent: A plea for early-stage diagnosis and full surgical treatment. Gynecol Surg 2015;12:21-30.

6 Stratton P, Berkley KJ: Chronic pelvic pain and endometriosis: Translational evidence of the relationship and implications. Hum Reprod Update 2011;17:327-346.

7 Sanchez AM, Vigano P, Somigliana E, Panina-Bordignon P, Vercellini P, Candiani M: The distinguishing cellular and molecular features of the endometriotic ovarian cyst: From pathophysiology to the potential endometrioma-mediated damage to the ovary. Hum Reprod Update 2014;20:217-230.

-8 Kitajima M, Defrere S, Dolmans MM, Colette S, Squifflet J, Van Langendonckt A, Donnez J: Endometriomas as a possible cause of reduced ovarian reserve in women with endometriosis. Fertil Sterility 2011;96:685691.

-9 Young VJ, Brown JK, Saunders PT, Duncan WC, Horne AW: The peritoneum is both a source and target of tgf-beta in women with endometriosis. PloS one 2014;9:e106773.

$>10$ Border WA, Noble NA: Transforming growth factor beta in tissue fibrosis. N Engl J Med 1994;331:12861292.

11 Beanes SR, Dang C, Soo C, Ting K: Skin repair and scar formation: The central role of tgf-beta. Expert Rev Mol Med 2003;5:1-22.

12 Willis BC, Borok Z: Tgf-beta-induced emt: Mechanisms and implications for fibrotic lung disease. Am J Physiol Lung Cell Mol Physiol 2007;293:L525-534.

13 Holmdahl L, Kotseos K, Bergstrom M, Falk P, Ivarsson ML, Chegini N: Overproduction of transforming growth factor-beta1 (tgf-beta1) is associated with adhesion formation and peritoneal fibrinolytic impairment. Surgery 2001;129:626-632.

14 McCormick LL, Zhang Y, Tootell E, Gilliam AC: Anti-tgf-beta treatment prevents skin and lung fibrosis in murine sclerodermatous graft-versus-host disease: A model for human scleroderma.J immunol 1999;163:5693-5699. 


\section{Cellular Physiology Cell Physiol Biochem 2018;46:1078-1090 and Biochemistry Published \begin{tabular}{l|l} 
DOI: 10.1159/000488838 & $\begin{array}{l}\text { C } 2018 \text { The Author(s). Published by S. Karger AG, Basel } \\
\text { www.karger.com/cpb }\end{array}$
\end{tabular}

15 Nakamura T, Sakata R, Ueno T, Sata M, Ueno H: Inhibition of transforming growth factor beta prevents progression of liver fibrosis and enhances hepatocyte regeneration in dimethylnitrosamine-treated rats. Hepatology 2000;32:247-255.

16 Pizzo A, Salmeri FM, Ardita FV, Sofo V, Tripepi M, Marsico S: Behaviour of cytokine levels in serum and peritoneal fluid of women with endometriosis. Gynecol Obstet Invest 2002;54:82-87.

17 Oosterlynck DJ, Meuleman C, Waer M, Koninckx PR: Transforming growth factor-beta activity is increased in peritoneal fluid from women with endometriosis. Obstet Gynecol 1994;83:287-292.

18 Omwandho COA, Konrad L, Halis G, Oehmke F, Tinneberg H-R: Role of tgf- $\beta$ s in normal human endometrium and endometriosis. Hum Reprod 2010;25:101-109.

-19 Martinez-Gonzalez J, Badimon L: The nr4a subfamily of nuclear receptors: New early genes regulated by growth factors in vascular cells. Cardiovasc Res 2005;65:609-618.

20 Pei L, Waki H, Vaitheesvaran B, Wilpitz DC, Kurland IJ, Tontonoz P: Nr4a orphan nuclear receptors are transcriptional regulators of hepatic glucose metabolism. Nature Med 2006;12:1048-1055.

21 Maxwell MA, Cleasby ME, Harding A, Stark A, Cooney GJ, Muscat GE: Nur77 regulates lipolysis in skeletal muscle cells. Evidence for cross-talk between the beta-adrenergic and an orphan nuclear hormone receptor pathway. J Biol Chem 2005;280:12573-12584.

22 Cheng Z, Volkers M, Din S, Avitabile D, Khan M, Gude N, Mohsin S, Bo T, Truffa S, Alvarez R, Mason M, Fischer KM, Konstandin MH, Zhang XK, Heller Brown J, Sussman MA: Mitochondrial translocation of nur77 mediates cardiomyocyte apoptosis. Eur Heart J2011;32:2179-2188.

-23 Zeng H, Qin L, Zhao D, Tan X, Manseau EJ, Van Hoang M, Senger DR, Brown LF, Nagy JA, Dvorak HF: Orphan nuclear receptor tr3/nur77 regulates vegf-a-induced angiogenesis through its transcriptional activity. J Exp Med 2006;203:719-729.

24 Winoto A, Littman DR: Nuclear hormone receptors in t lymphocytes. Cell 2002;109 Suppl:S57-66.

25 Zhou F, Drabsch Y, Dekker TJ, de Vinuesa AG, Li Y, Hawinkels LJ, Sheppard KA, Goumans MJ, Luwor RB, de Vries CJ, Mesker WE, Tollenaar RA, Devilee P, Lu CX, Zhu H, Zhang L, Dijke PT: Nuclear receptor nr4a1 promotes breast cancer invasion and metastasis by activating tgf-beta signalling. Nature Comm 2014;5:3388.

-26 Palumbo-Zerr K, Zerr P, Distler A, Fliehr J, Mancuso R, Huang J, Mielenz D, Tomcik M, Furnrohr BG, Scholtysek C, Dees C, Beyer C, Kronke G, Metzger D, Distler O, Schett G, Distler JH: Orphan nuclear receptor nr4a1 regulates transforming growth factor-beta signaling and fibrosis. Nat Med 2015;21:150-158.

27 Zhan Y, Du X, Chen H, Liu J, Zhao B, Huang D, Li G, Xu Q Zhang M, Weimer BC, Chen D, Cheng Z, Zhang L, Li Q, Li S, Zheng Z, Song S, Huang Y, Ye Z, Su W, Lin SC, Shen Y, Wu Q: Cytosporone b is an agonist for nuclear orphan receptor nur77 Nat Chem Biol 2008;4:548-556.

28 Matsuzaki S, Darcha C: In vitro effects of a small-molecule antagonist of the tcf/ss-catenin complex on endometrial and endometriotic cells of patients with endometriosis. PloS one 2013;8:e61690.

-29 Matsuzaki S, Darcha C: Antifibrotic properties of epigallocatechin-3-gallate in endometriosis. Hum Reprod (Oxford, England) 2014;29:1677-1687.

-30 Eaton JL, Unno K, Caraveo M, Lu Z, Kim JJ: Increased akt or mek1/2 activity influences progesterone receptor levels and localization in endometriosis. J Clin Endocrinol Metabol 2013;98:E1871-E1879.

-31 Matsuzaki S, Darcha C, Maleysson E, Canis M, Mage G: Impaired down-regulation of e-cadherin and betacatenin protein expression in endometrial epithelial cells in the mid-secretory endometrium of infertile patients with endometriosis. JClin Endocrinol Metabol 2010;95:3437-3445.

-32 Cummings AM, Metcalf JL: Induction of endometriosis in mice: A new model sensitive to estrogen. Reprod Toxicol (Elmsford, NY) 1995;9:233-238.

33 Agostinis C, Zorzet S, De Leo R, Zauli G, De Seta F, Bulla R: The combination of n-acetyl cysteine, alphalipoic acid, and bromelain shows high anti-inflammatory properties in novel in vivo and in vitro models of endometriosis. Mediat Inflamm 2015;2015:918089.

-34 Matsuzaki S, Darcha C: Involvement of the wnt/beta-catenin signaling pathway in the cellular and molecular mechanisms of fibrosis in endometriosis. PloS one 2013;8:e76808.

35 Zuo F, Kaminski N, Eugui E, Allard J, Yakhini Z, Ben-Dor A, Lollini L, Morris D, Kim Y, DeLustro B, Sheppard D, Pardo A, Selman M, Heller RA: Gene expression analysis reveals matrilysin as a key regulator of pulmonary fibrosis in mice and humans. Proc Nat Acad Sci U S A 2002;99:6292-6297. 


\section{Cellular Physiology Cell Physiol Biochem 2018;46:1078-1090

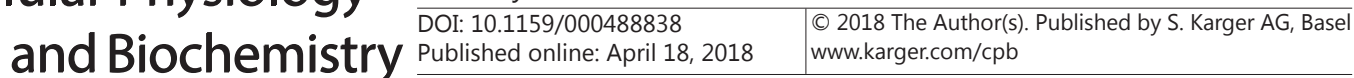

-36 Verhage RJ, Ruiz A, Verheem A, Goldschmeding R, Borel Rinkes IH, van Hillegersberg R: Fibrin-thrombin coated sealant increases strength of esophagogastric anastomoses in a rat model. J Surg Res 2012;176:e5763.

-37 Xiao ZW, Zhang W, Ma L, Qiu ZW: Therapeutic effect of magnesium isoglycyrrhizinate in rats on lung injury induced by paraquat poisoning. Eur Rev Med Pharmacol Scie 2014;18:311-320.

-38 Wynn TA: Common and unique mechanisms regulate fibrosis in various fibroproliferative diseases. J Clin Invest 2007;117:524-529.

-39 Wynn TA: Integrating mechanisms of pulmonary fibrosis. J Exp Med 2011;208:1339-1350.

-40 Lopez-Novoa JM, Nieto MA: Inflammation and emt: An alliance towards organ fibrosis and cancer progression. EMBO Mol Med 2009;1:303-314.

41 Bataller R, Brenner DA: Liver fibrosis. J Clin Inv 2005;115:209-218.

42 Vercellini P, Vigano P, Somigliana E, Fedele L: Endometriosis: Pathogenesis and treatment. Nature reviews Endocrinology 2014;10:261-275.

43 Li J, Cen B, Chen S, He Y: Microrna-29b inhibits tgf-beta1-induced fibrosis via regulation of the tgf-beta1/ smad pathway in primary human endometrial stromal cells. Mol Med Rep 2016;13:4229-4237.

44 Liu JJ, Zeng HN, Zhang LR, Zhan YY, Chen Y, Wang Y, Wang J, Xiang SH, Liu WJ, Wang WJ, Chen HZ, Shen YM, Su WJ, Huang PQ Zhang HK, Wu Q: A unique pharmacophore for activation of the nuclear orphan receptor nur77 in vivo and in vitro. Cancer Res 2010;70:3628-3637.

45 Moll UM, Marchenko N, Zhang XK: P53 and nur77/tr3 - transcription factors that directly target mitochondria for cell death induction. Oncogene 2006;25:4725-4743.

-46 Xie X, Song X, Yuan S, Cai H, Chen Y, Chang X, Liang B, Huang D: Histone acetylation regulates orphan nuclear receptor nr4a1 expression in hypercholesterolaemia. Clin Sci 2015;129:1151-1161.

47 Wu J, Liu J, Jia R, Song H: Nur77 inhibits androgen-induced bladder cancer growth. Cancer Invest 2013;31:654-660.

48 Li QX, Ke N, Sundaram R, Wong-Staal F: Nr4a1, 2, 3--an orphan nuclear hormone receptor family involved in cell apoptosis and carcinogenesis. Histol Histopathol 2006;21:533-540.

49 Wingate AD, Arthur JS: Post-translational control of nur77 Biochem Soc Trans 2006;34:1107-1109.

50 Fahrner TJ, Carroll SL, Milbrandt J: The ngfi-b protein, an inducible member of the thyroid/steroid receptor family, is rapidly modified posttranslationally. Mol Cell Biol 1990;10:6454-6459.

-51 van Tiel CM, Kurakula K, Koenis DS, van der Wal E, de Vries CJ: Dual function of pin1 in nr4a nuclear receptor activation: Enhanced activity of nr4as and increased nur77 protein stability. Biochim Biophys Act 2012;1823:1894-1904.

52 Jiang Y, Jiang R, Cheng X, Zhang Q, Hu Y, Zhang H, Cao Y, Zhang M, Wang J, Ding L, Diao Z, Sun H, Yan G: Decreased expression of nr4a nuclear receptors in adenomyosis impairs endometrial decidualization. Mol Hum Reprod 2016;22:655-668.

53 Saare M, Rekker K, Laisk-Podar T, Rahmioglu N, Zondervan K, Salumets A, Gotte M, Peters M: Challenges in endometriosis mirna studies - from tissue heterogeneity to disease specific mirnas. Biochim Biophys Act 2017;1863:2282-2292.

54 Chen HZ, Zhao BX, Zhao WX, Li L, Zhang B, Wu Q: Akt phosphorylates the tr3 orphan receptor and blocks its targeting to the mitochondria. Carcinogenesis 2008;29:2078-2088.

55 Li J, Lv C, Sun W, Li Z, Han X, Li Y, Shen Y: Cytosporone b, an inhibitor of the type iii secretion system of salmonella enterica serovar typhimurium. Antimicrob Agents Chemother 2013;57:2191-2198. 